\title{
Downregulation of miRNA-663b protects against hypoxia-induced injury in cardiomyocytes by targeting BCL2L1
}

\author{
FEI YU ${ }^{1 *}$, XUESONG ZHANG ${ }^{2 *}$, CAIQIN SUN ${ }^{1}$, WEIYI XU ${ }^{3}$ and JUNYANG XIA ${ }^{4}$ \\ ${ }^{1}$ Cardiovascular Department, Internal Medicine Department; ${ }^{2}$ Central Laboratory; ${ }^{3}$ Operating Room; \\ ${ }^{4}$ Hospital Office Department, Jingjiang People's Hospital, Jingjiang, Jiangsu 214500, P.R. China
}

Received June 25, 2019; Accepted March 17, 2020

DOI: $10.3892 /$ etm.2020.8644

\begin{abstract}
In the present study, the role of microRNA-663b (miR-663b) in cardiomyocyte injury was examined. Reverse transcription-quantitative PCR (RT-qPCR) was performed to detect miR-663b expression in hypoxia-induced H9c2 cells. The results revealed that miR-663b expression was significantly upregulated in hypoxia-induced H9c2 cells compared with control cells. TargetScan analysis and dual-luciferase reporter assays demonstrated that miR-663b directly targeted the B-cell lymphoma 2 like 1 (BCL2L1) gene. RT-qPCR and western blotting data indicated that BCL2L1 expression was significantly downregulated in hypoxia-induced H9c2 cells compared with control cells. Under hypoxic conditions, H9c2 cells were transfected with miR-663b inhibitor, inhibitor control, miR-663b inhibitor + control small interfering (si)RNA or miR-663b inhibitor + BCL2L1-siRNA for $48 \mathrm{~h}$. ELISA against creatine kinase-muscle/brain (CK-MB) and cardiac troponin 1 (cTnI) demonstrated that the miR-663b inhibitor reduced CK-MD and CTnI release and increased mitochondrial viability when compared with hypoxia-treated cells. Additionally, the miR-663b inhibitor significantly increased H9c2 cell viability and decreased cell apoptosis under hypoxic conditions. The results of ELISA further revealed that the miR-663b inhibitor decreased the release of various inflammatory factors, including tumour necrosis factor $\alpha$, interleukin (IL) $1 \beta$ and IL-6 in H9c2 cells under hypoxic conditions. These changes were reversed following BCL2L1 knockdown. In conclusion, miR-663b inhibition protected cardiomyocytes against hypoxia-induced injury by targeting BCL2L1 and may potentially be a novel target for the treatment of patients with myocardial infarction.
\end{abstract}

Correspondence to: Dr Junyang Xia, Hospital Office Department, Jingjiang People's Hospital, 28 Zhongzhou Road, Jingjiang, Jiangsu 214500, P.R. China

E-mail: xiajy062019@163.com

${ }^{*}$ Contributed equally

Key words: myocardial infarction, microRNA-663b, B-cell lymphoma 2 like 1 , hypoxia

\section{Introduction}

Coronary heart disease is a major cause of death and disability that causes serious debilitation in patients, with an incidence rate that is increasing on a yearly basis $(1,2)$. Acute myocardial infarction (MI) is a coronary heart disease with high worldwide incidence and mortality rates that leads to myocardial tissue injury and ultimately disability or death (3). Hypoxia is one of the primary causes of MI. Under hypoxic conditions, changes in energy metabolism occur during mitochondrial respiration in which anaerobic glycolysis results in numerous physiological and pathological reactions leading to acidosis and necrosis (4). Therefore, understanding the pathogenesis of MI may highlight potentially novel targets to limit damage.

MicroRNAs (miRNAs or miRs) are small single-stranded non-coding RNAs that are 22-25 nucleotides in length $(5,6)$. miRNAs post-transcriptionally regulate gene expression (7-9) and mediate the degradation of or inhibit the translation of mRNAs by directly binding to their $3^{\prime}$ untranslated region (3'-UTR) $(10,11)$. Numerous studies have demonstrated that miRNAs serve an important role in the pathogenesis of many types of cancer (12-14), including miR-663b, indicating that they may be involved in the occurrence and development of tumors (15).

Pan et al (16) demonstrated that miR-663b is downregulated in gastric cancer and Jiao et al (17) revealed that expression was increased in castration-resistant prostate cancer. Additionally, miR-663b is upregulated in nasopharyngeal carcinoma (18). Liang et al (19) demonstrated that miR-663b promoted proliferation by targeting tumor suppressor candidate 2 and that the resulting upregulation was associated with advanced clinical stage cancer and lymph node metastasis. miR-663b expression is also upregulated in patients with MI (20). However, its role and function in MI remain unknown.

The aim of the present study was to determine whether miR-663b served a role in hypoxia-induced cardiomyocyte injury in vitro and to study the specific underlying molecular mechanisms. The present study may provide a theoretical basis for the development of novel strategies for the treatment of MI.

\section{Materials and methods}

Cell culture and transfection. Rat cardiomyocyte H9c2 cells were purchased from the Cell Bank of the Type Culture 
Collection of the Chinese Academy of Sciences. H9c2 cells were cultured in DMEM (Gibco; Thermo Fisher Scientific, Inc.) supplemented with 10\% FBS (Gibco; Thermo Fisher Scientific, Inc.) and incubated at $37^{\circ} \mathrm{C}$ with $5 \% \mathrm{CO}_{2}$. To simulate hypoxic damage, cells were incubated for $48 \mathrm{~h}$ at $37^{\circ} \mathrm{C}$ with $94 \% \mathrm{~N}_{2}, 5 \% \mathrm{CO}_{2}$ and $1 \% \mathrm{O}_{2}(21)$. Cells in the control group were incubated at $37^{\circ} \mathrm{C}$ with $5 \% \mathrm{CO}_{2}$.

Under hypoxic conditions, $\mathrm{H} 9 \mathrm{c} 2$ cells were transfected with $50 \mathrm{nM}$ miR-663b inhibitor (5'-GCGGUCCCGCGGCGCCCC GCCU-3'; Shanghai GenePharma Co., Ltd.), $50 \mathrm{nM}$ inhibitor control (5'-UUGUACUACACAAAAGUACUG-3'; Shanghai GenePharma Co., Ltd.), $50 \mathrm{nM}$ miR-663b inhibitor $+1 \mu \mathrm{M}$ control-small interfering (si)RNA (cat. no. sc-36869; Santa Cruz Biotechnology, Inc.) or $50 \mathrm{nM}$ miR-663b inhibitor + $1 \mu \mathrm{M}$ B-cell lymphoma 2 like 1 (BCL2L1)-siRNA (cat. no. sc-29216; Santa Cruz Biotechnology, Inc.) for $48 \mathrm{~h}$ using Lipofectamine ${ }^{\circledR} 2000$ (Invitrogen; Thermo Fisher Scientific, Inc.) according to the manufacturer's protocol. Transfection efficiency was assessed using reverse transcription quantitative PCR (RT-qPCR) $48 \mathrm{~h}$ after experimentation.

$R T-q P C R$. Total RNA was extracted from H9c2 cells using TRIzol ${ }^{\circledR}$ reagent (Invitrogen; Thermo Fisher Scientific, Inc.). RNA was reverse transcribed into cDNA using a cDNA Reverse Transcription kit (Vazyme, Biotech Co., Ltd.) at a temperature of $42^{\circ} \mathrm{C}$ for $60 \mathrm{~min}$ and $75^{\circ} \mathrm{C}$ for $5 \mathrm{~min}$. qPCR was performed using a SYBR ${ }^{\mathrm{TM}}$ Green PCR Master kit (Vazyme Biotech Co., Ltd.). The thermocycling conditions were as follows: Initial denaturation at $95^{\circ} \mathrm{C}$ for $3 \mathrm{~min}$; followed by 40 cycles of $95^{\circ} \mathrm{C}$ for $30 \mathrm{sec}, 56^{\circ} \mathrm{C}$ for $30 \mathrm{sec}$ and $72^{\circ} \mathrm{C}$ for $30 \mathrm{sec}$. Primer sequences used for PCR were listed as follows: miR-663b forward, 5'-CGCTAACAGTCTCCAGTC-3' and reverse 5'-GTGCAGGGTCCGAGGT-3'; BCL2L1 forward, 5'-GACTGA ATCGGAGATGGAGACC-3' and reverse 5'-GCAGTTCAAACTCGTCGCCT-3'; U6, 5'-GCTTCGGCA GCACATATACTAAAAT-3'; reverse, 5'-CGCTTCACGAAT TTGCGTGTCAT-3'; GAPDH forward, 5'-CTTTGGTATCGT GGAAGGACTC-3' and reverse, 5'-GTAGAGGCAGGGATG ATGTTCT-3'. The fold change of gene expression was calculated using the $2^{-\Delta \Delta C q}$ method (22). U6 and GAPDH were used as the internal controls for normalizing expression of miRNA and mRNA, respectively. All experiments were performed in triplicate.

Dual-luciferase reporter assay. TargetScan analysis (version 7.2; http://www.targetscan.org/vert_72/) was performed to examine the association between miRNA-663b and BCL2L1. The results indicated that miR-663b binding sites were present in BCL2L1. To confirm binding between miR-663 and BCL2L1, a dual luciferase reporter assay was performed.

Luciferase reported plasmids (psi-CHECK2) containing BCL2L1 wild-type (WT-BCL2L1) or mutant (MUT-BCL2L1) 3'-UTRs were synthesized by TsingKe Biotech Co. H9c2 cells were co-transferred with WT-BCL2L1 or MUT-BCL2L1 luciferase reporter plasmids and the miR-663b mimic or mimic control, respectively, using Lipofectamine ${ }^{\circledR} 2000$ (Invitrogen; Thermo Fisher Scientific, Inc.). Cells were harvested 48 h after transfection and luciferase activity was measured using a Dual-Luciferase ${ }^{\circledast}$ Reporter Assay system (Promega

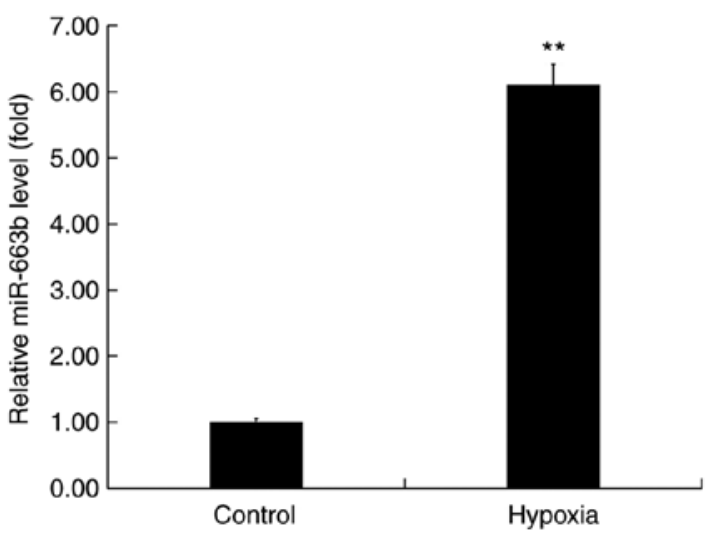

Figure 1. Expression of miR-663b in hypoxia-induced H9c2 cells. H9c2 cells were cultured in hypoxic conditions for $48 \mathrm{~h}$. Reverse transcription-quantitative PCR was performed to detect the expression of miR-663b. Data are presented as the mean \pm standard deviation of three independent experiments ${ }^{* *} \mathrm{P}<0.01$ vs. control group. miR, microRNA.

Corporation) according to the manufacturer's protocol. Firefly luciferase was used to normalize data.

Western blotting. Total protein was extracted from H9c2 cells using RIPA lysis buffer (Beijing Solarbio Science \& Technology Co., Ltd.) at room temperature for $30 \mathrm{~min}$, after which samples were stored at $-20^{\circ} \mathrm{C}$. A bicinchoninic acid assay kit (Pierce; Thermo Fisher Scientific, Inc.) was used to quantify protein concentration. Equal quantities of protein $(30 \mu \mathrm{g} /$ lane) were loaded onto a $15 \%$ gel, resolved using SDS-PAGE and transferred onto PVDF membranes (EMD Millipore). Membranes were blocked with 5\% skimmed milk in TBS containing $0.1 \%$ Tween at room temperature for $2 \mathrm{~h}$. Subsequently, the membranes were incubated with the following primary antibodies: Anti-BCL2L1 (cat. no. sc-70418; 1:1,000; Santa Cruz Biotechnology, Inc.), anti-cleaved-Caspase-3 (cat. no. ab2302; 1:1,000; Abcam) or anti-GAPDH (cat. no. 5174; 1:1,000; Cell Signaling Technology, Inc.) at $4^{\circ} \mathrm{C}$ overnight. The membranes were incubated with horseradish peroxidase-conjugated goat anti-rabbit immunoglobulin G secondary antibodies (cat. no. 7074; 1:2,000; Cell Signaling Technology, Inc.) at room temperature for $2 \mathrm{~h}$. Signals were visualized using enhanced chemiluminescence reagent (EMD Millipore) and GAPDH was used as the loading control.

Flow cytometry analysis. Transfected cells $\left(1 \times 10^{6}\right.$ cells $)$ were harvested, centrifuged at a low temperature at a high speed $\left(1,000 \times \mathrm{g} ; 4^{\circ} \mathrm{C} ; 5 \mathrm{~min}\right)$ and re-suspended in $200 \mu 1$ binding buffer containing $10 \mu \mathrm{l}$ fluorescein isothiocyanate-annexin $\mathrm{V}$. After centrifugation, cells were re-suspended in $5 \mu 1$ propidium iodide (PI) and $300 \mu \mathrm{l}$ PBS, and incubated for $30 \mathrm{~min}$ at room temperature in the dark. Cells were then stained using annexin-V/PI Apoptosis Detection kit (BD Biosciences) according to the manufacturer's protocol. Fluorescence was assessed using a BD FACSCalibur ${ }^{\mathrm{TM}}$ flow cytometer (Becton, Dickinson and Company) and flow data was analyzed using FlowJo (version 7.6.1; FlowJo LLC).

MTT assay. H9c2 cells were transfected with miR-663b inhibitor, inhibitor control, miR-663b inhibitor + control-siRNA or 


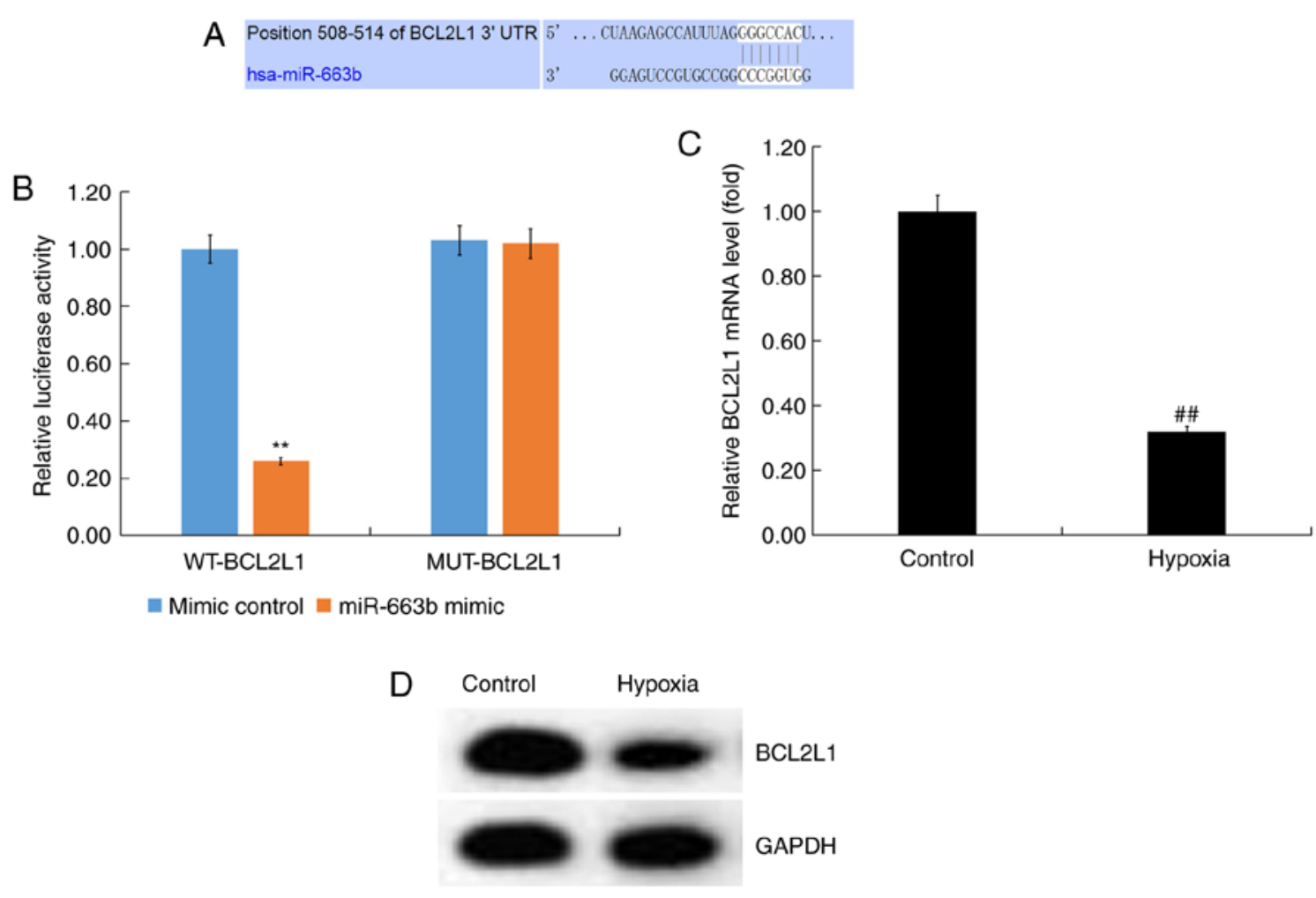

Figure 2. BCL2L1 is a target gene of miR-663b. (A) Prediction of miR-663b binding to BCL2L1 using TargetScan. (B) A dual luciferase reporter assay was performed to confirm binding between miR-663b and BCL2L1. (C) Reverse transcription-quantitative PCR and (D) western blotting were performed to determine the expression of BCL2L1. Data are presented as the mean \pm standard deviation of three independent experiments. ${ }^{* *} \mathrm{P}<0.01$ vs. mimic control group; ${ }^{\# \#} \mathrm{P}<0.01$ vs. control group. BCL2L1, B-cell lymphoma 2 like 1; WT, wild type; MUT, mutant; miR, microRNA.

miR-663b inhibitor + BCL2L1-siRNA for $48 \mathrm{~h}$ under hypoxic conditions. Transfected cells were then plated in a 96-well plate at a density of $5 \times 10^{3}$ cells/well. After $24 \mathrm{~h}$ of incubation at $37^{\circ} \mathrm{C}, 20 \mu \mathrm{l} \mathrm{MTT}$ reagent (Sigma-Aldrich; Merck KGaA) was added to each well. Following a further $4 \mathrm{~h}$ of incubation at $37^{\circ} \mathrm{C}, 150 \mu \mathrm{l} \mathrm{DMSO}$ was added to each well and agitated for $15 \mathrm{~min}$ in the dark. Optical density values were measured at $490 \mathrm{~nm}$ using a microplate reader.

ELISA. Levels of certain inflammatory cytokines, including tumour necrosis factor $\alpha$ (TNF- $\alpha$; cat. no. PT516), interleukin (IL) $1 \beta$ (cat. no. PI303) and IL-6 (cat. no. PI328) in cell supernatants were detected using specific ELISA kits (Beyotime Institute of Biotechnology) according to the manufacturer's protocol.

Assessment of cellular injury. Following treatment, the release of various cardiomyocyte injury biomarkers, including creatine kinase-muscle/brain (CK-MB; cat. no. CSB-E14403r; Cusabio Technology LLC) and cardiac troponin I (cTnI; cat. no. CSB-E08594r; Cusabio Technology LLC) was determined using specific ELISA kits according to the manufacturer's protocol. Mitochondrial viability was measured using a mitochondrial viability staining kit (cat. no. ab129732; Abcam) according to the manufacturer's protocol.

Statistical analysis. Statistical analyses were performed using GraphPad Prism software (version 5; GraphPad Software, Inc.). Statistical differences between groups were determined using a Student's t-test or one-way ANOVA followed by Tukey's post hoc test. Data are expressed as the mean \pm standard deviation of at least three independent experiments. $\mathrm{P}<0.05$ was considered to indicate a statistically significant difference.

\section{Results}

miR-663b expression is significantly increased in hypoxia-induced H9c 2 cells. To examine the role of miR-663b in hypoxia-induced H9c2 cells, miR-663b expression was assessed using RT-qPCR. The results revealed that miR-663b expression was significantly upregulated in $\mathrm{H} 9 \mathrm{c} 2$ cells compared with the control group (Fig. 1), indicating that miR-663b may be associated with the development of MI.

$B C L 2 L 1$ is a direct target gene of $m i R-663 b$. To determine the role and mechanism by which miR-663 exerted its effects, bioinformatics analysis was performed using TargetScan to predict miR-663b targets. BCL2L1 was predicted to be a target gene of miR-663b (Fig. 2A).

The 3'-UTR (WT or MUT) of BCL2L1 was inserted into the pmiR luciferase reporter and $\mathrm{H} 9 \mathrm{c} 2$ cells were co-transfected with the miR-663b mimic and luciferase reporter plasmid. The results revealed that miR-663b mimic co-transfection with the WT-BCL2L1 3'-UTR reporter inhibited luciferase activity while $\mathrm{miR}-663 \mathrm{~b}$ mimic had no effect on the reporter containing the MUT-BCL2L1 3'-UTR (Fig. 2B). These data suggested that BCL2L1 was a direct target gene of miR-663b. 

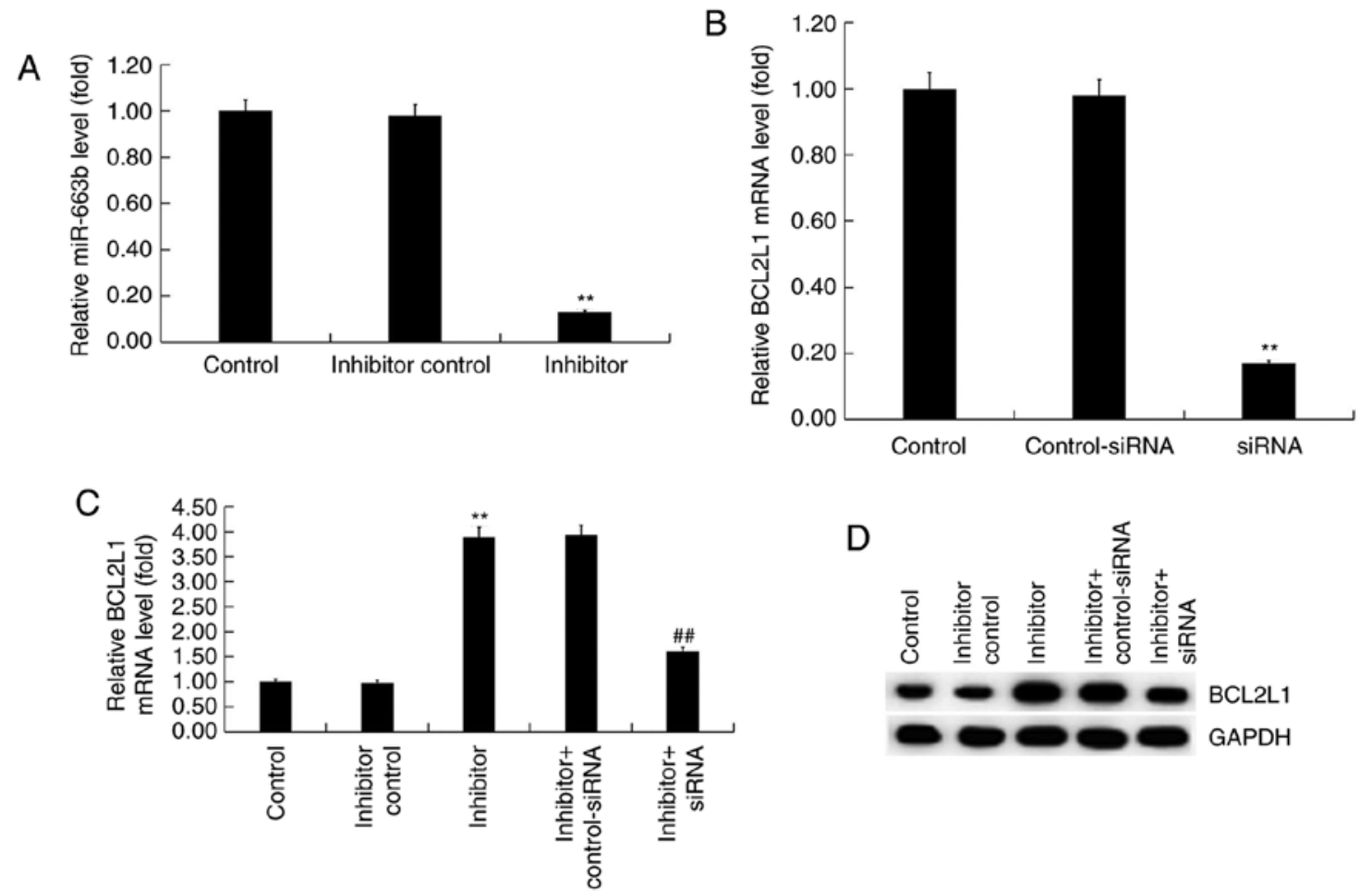

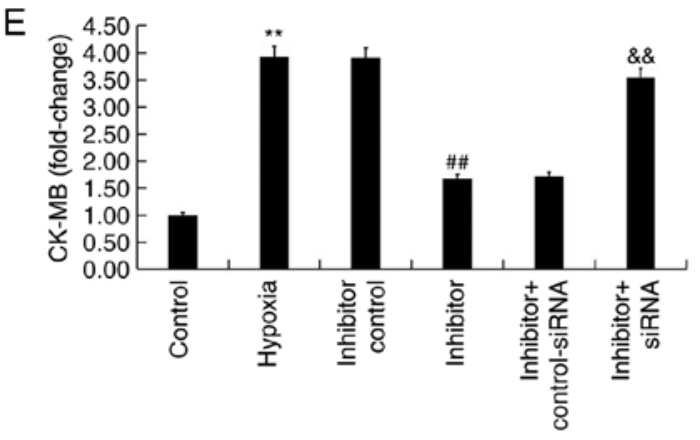

Hypoxia

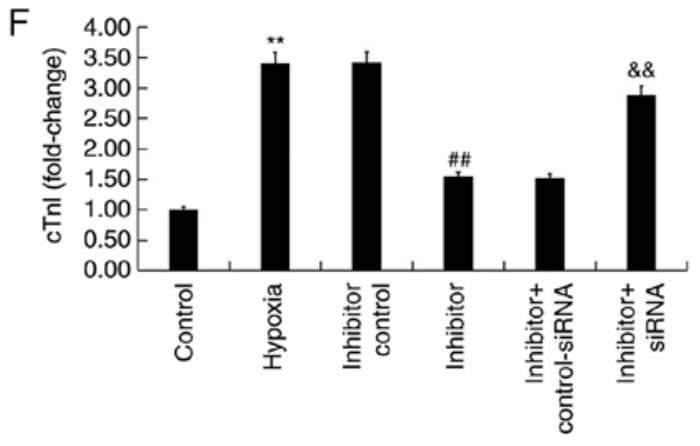

Hypoxia

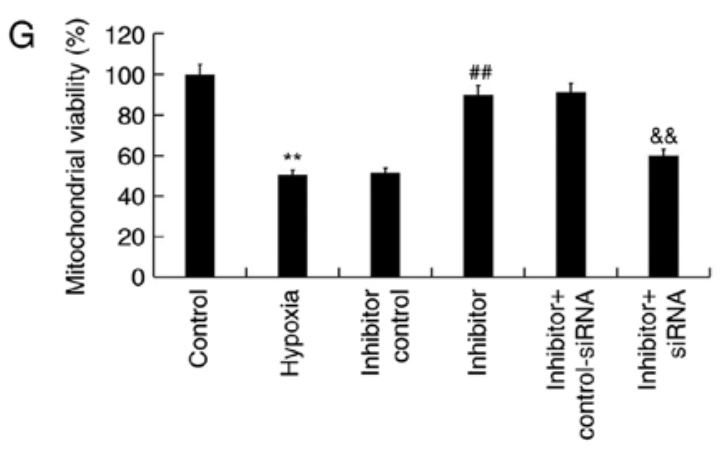

Hypoxia

Figure 3. Effect of the miR-663b inhibitor on H9c2 hypoxia-induced cell injury. (A) miR-663b expression in transfected H9c2 cells. (B) mRNA expression of BCL2L1 in transfected H9c2. (C) BCL2L1 mRNA and (D) protein levels in transfected H9c2 cells. Release of (E) CK-MB and (F) cTnI. (G) Mitochondrial viability. Data are presented as the mean \pm standard deviation of three independent experiments. ${ }^{* *} \mathrm{P}<0.01 \mathrm{vs}$. control group; ${ }^{\# \#} \mathrm{P}<0.01 \mathrm{vs}$. hypoxia group; ${ }^{\&}{ }^{\&} \mathrm{P}<0.01$ vs. hypoxia + inhibitor group. miR, microRNA; BCL2L1, B-cell lymphoma 2 like 1; siRNA, small interfering RNA; CK-MB, creatine kinase-muscle/brain; CTn1, Cardiac troponin 1.

Subsequently,the expression of BCL2L1 inhypoxia-induced H9c2 cells was determined. RT-qPCR and western blotting demonstrated that BCL2L1 expression was downregulated in hypoxia-induced $\mathrm{H} 9 \mathrm{c} 2$ cells (Fig. 2C and D).
Effect of miR-663b inhibitor on H9c2 cell injury induced by hypoxia. $\mathrm{H} 9 \mathrm{c} 2$ cells were transfected with inhibitor control or miR-663b inhibitor for $48 \mathrm{~h}$. RT-qPCR revealed that the miR-663b inhibitor significantly reduced 


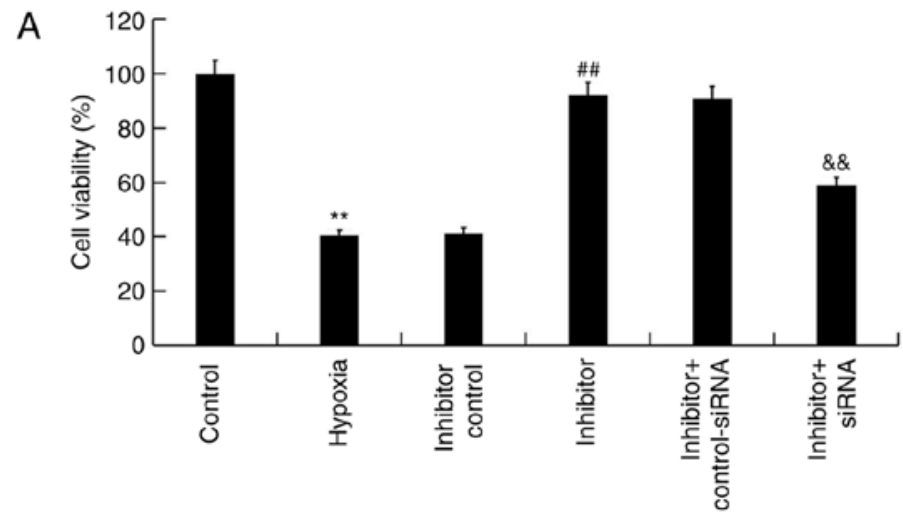

Hypoxia

B
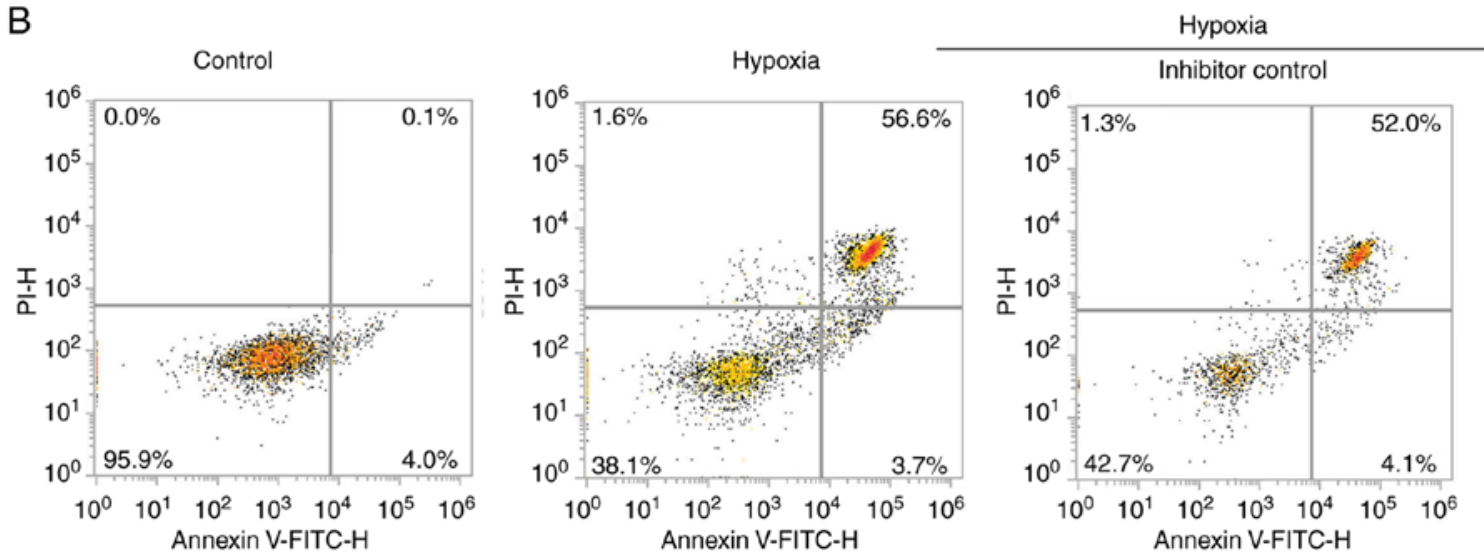

Hypoxia
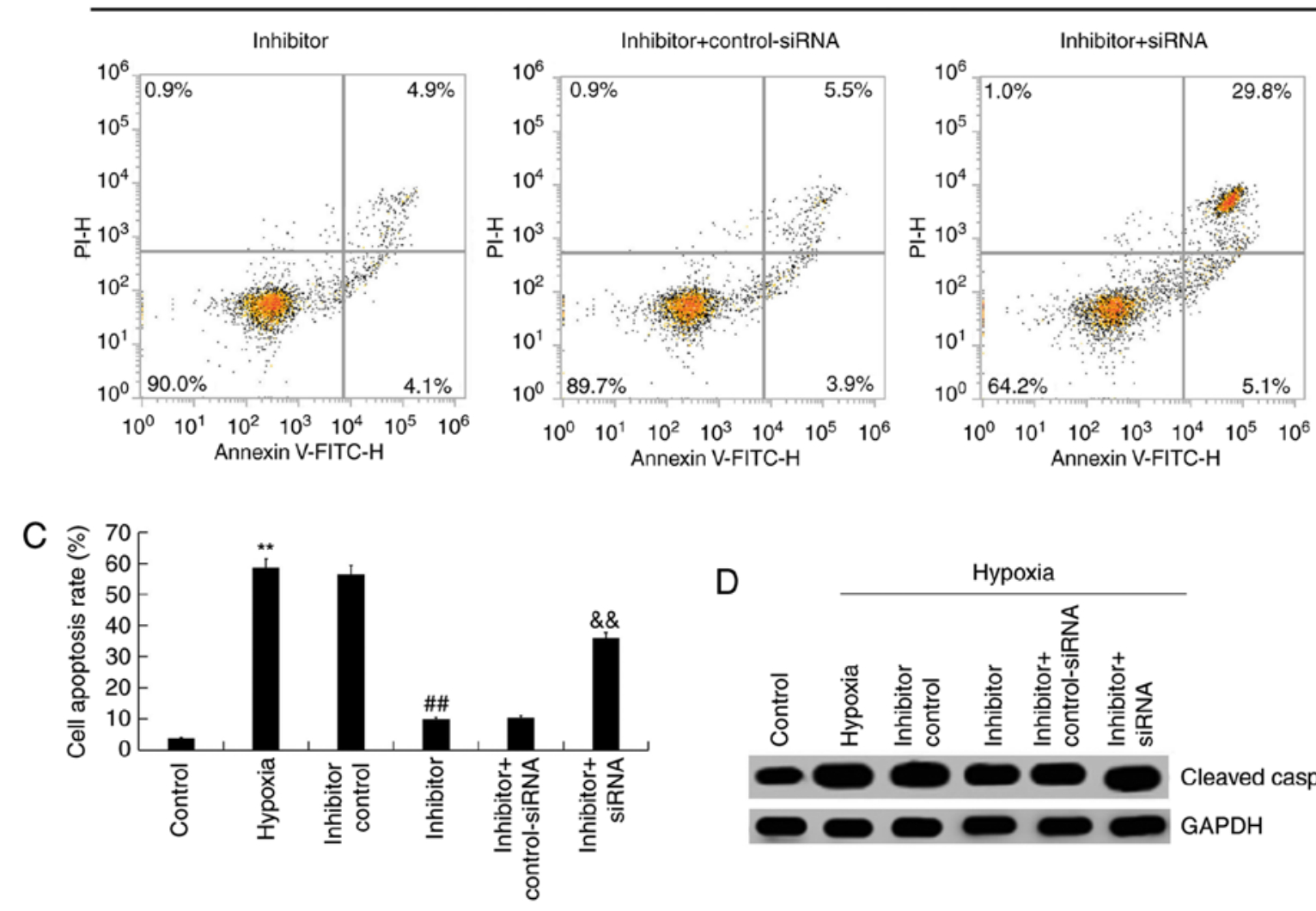

D

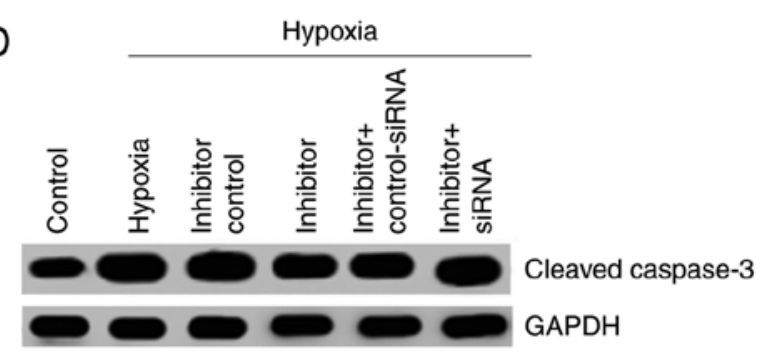

Hypoxia

Figure 4. miR-663b inhibitor increases hypoxia-induced H9c2 cell viability and reduces apoptosis. (A) An MTT assay was used to detect cell viability. (B) Flow cytometry combined with (C) annexin V/PI staining was performed to measure apoptosis. (D) Western blotting was used to demonstrate cleaved-Caspase-3 protein expression levels in $\mathrm{H} 9 \mathrm{c} 2$ cells. Data are presented as the mean \pm standard deviation of three independent experiments. ${ }^{* *} \mathrm{P}<0.01$ vs. control group; ${ }^{\# \#} \mathrm{P}<0.01$ vs. hypoxia group; ${ }^{\& \&} \mathrm{P}<0.01$ vs. hypoxia + inhibitor group. PI, propidium iodide; miR, microRNA; si, small interfering. 


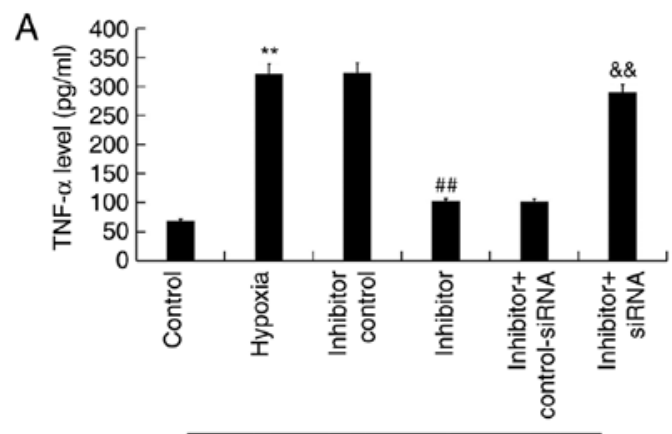

Hypoxia

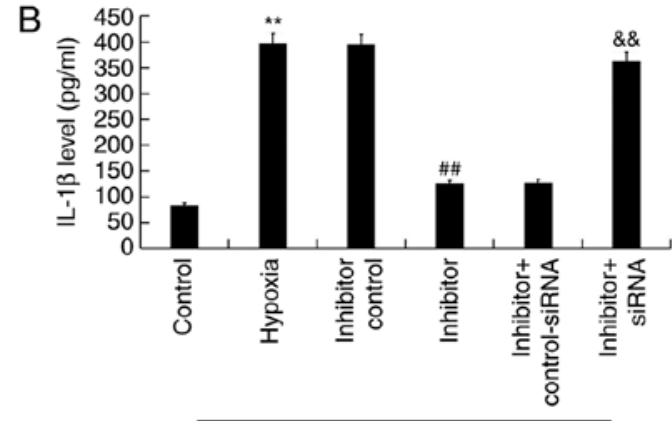

Hypoxia

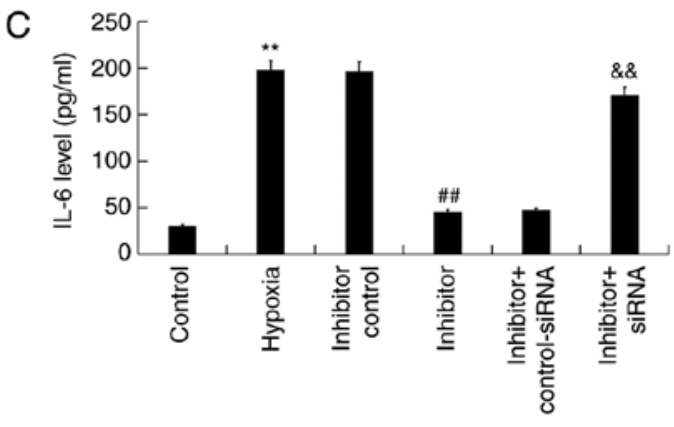

Hypoxia

Figure 5. miR-663b inhibitor decreases TNF- $\alpha$, IL-1 $\beta$ and IL-6 expression in H9c2 cells under hypoxic conditions. ELISA was performed to measure the levels of (A) TNF- $\alpha,(B)$ IL-1 $\beta(\mathrm{C})$ and IL-6. Data are presented as the mean \pm standard deviation of three independent experiments. ${ }^{* *} \mathrm{P}<0.01$ vs. control group; ${ }^{\#} \mathrm{P}<0.01$ vs. hypoxia group; ${ }^{\&} \mathrm{P}<0.01$ vs. hypoxia + inhibitor group. miR, microRNA; TNF- $\alpha$, tumor necrosis factor $\alpha$; IL, interleukin; siRNA, small interfering RNA.

miR-663 expression in H9c2 cells compared with controls (Fig. 3A). Additionally, H9c2 cells were transfected with BCL2L1-siRNA or control-siRNA. RT-qPCR results revealed that BCL2L1-siRNA significantly decreased the expression of BCL2L1 at the mRNA level in H9c2 cells compared with controls (Fig. 3B). Subsequently, H9c2 cells were co-transfected with miR-663b inhibitor + control-siRNA, or miR-663b inhibitor + BCL2L1-siRNA. RT-qPCR and western blotting results revealed that miR-663b inhibitor significantly increased the expression of BCL2L1 at the mRNA level and that this increase was reversed by BCL2L1-siRNA (Fig. 3C). Similar results were observed at the protein level as determined via western blotting (Fig. 3D).

The effect of miR-663b on hypoxia-induced cell damage was determined by detecting the release of two biomarkers associated with cardiomyocyte injury, CK-MB and cTnI. Compared with the controls, hypoxia significantly increased the release of CK-MB and cTnI whereas the miR-663b inhibitor significantly decreased CK-MB (Fig. 3E) and cTnI release (Fig. 3F). Transfection of BCL2L1-siRNA abolished the aforementioned changes. Furthermore, hypoxia also significantly reduced mitochondrial viability while miR-663b inhibitor improved mitochondrial viability in H9c2 cells (Fig. 3G). These changes were reversed by transfection of BCL2L1-siRNA.

Effect of miR-663b inhibitor on cell growth of hypoxia-induced $H 9 c 2$ cells. Under hypoxic conditions, H9c2 cells were transfected with inhibitor control, miR-663b inhibitor, miR-663b inhibitor + control-siRNA or miR-663b inhibitor +
BCL2L1-siRNA for $48 \mathrm{~h}$, after which an MTT assay was performed to measure cell viability. The results revealed that hypoxia significantly decreased the viability of H9c2 cells, whereas miR-663b inhibitor increased cell viability. This change was reversed by BCL2L1-siRNA when compared with the controls (Fig. 4A). Flow cytometry was subsequently performed to detect the proportion of apoptotic cells. The results revealed that hypoxia induced cell apoptosis and that the miR-663b inhibitor decreased cell apoptosis in the hypoxic cells compared with controls. These changes were reversed following BCL2L1-siRNA transfection (Fig. 4B and C).

The protein expression of cleaved-Caspase-3 was determined via western blotting. The results indicated that the hypoxia-induced upregulation of cleaved-Caspase- 3 protein expression in $\mathrm{H} 9 \mathrm{c} 2$ cells was significantly reduced in cells transfected with miR-663b inhibitor. This reduction was reversed following transfection with BCL2L1-siRNA (Fig. 4D). Together, the results indicated that the miR-663b inhibitor increased the viability of hypoxia-induced H9c2 cells and decreased cell apoptosis.

Effect of miR-663b inhibitor on the secretion of inflammatory factors in hypoxia-induced H9c2 cells. ELISA was performed to detect the effects of miR-663b inhibitor on the secretion of certain inflammatory factors in hypoxia-induced $\mathrm{H} 9 \mathrm{c} 2$ cells. Compared with the control group, hypoxia increased the release of TNF- $\alpha$, IL-1 $\beta$ and IL- 6 while miR-663b inhibitor transfection significantly decreased their release (Fig. 5A-C). Knocking down BCL2L1 expression using siRNA reversed these effects. 


\section{Discussion}

Acute MI is characterized by ischemic injury and cardiomyocyte cell death, which leads to cardiac dysfunction and eventual heart failure (3). Cardiomyocyte apoptosis is one of the primary types of cardiac cell death during MI (23). Protecting cardiomyocytes against hypoxia-induced damage may therefore be a promising therapeutic target for the treatment of MI (24-26).

miRNAs serve an important role in the development of MI. Xiao et al (27) demonstrated that miR-24-3p decreased apoptosis in mouse cardiomyocytes in response to ischemia/reperfusion (I/R) injury. Zhang et al (2) also revealed that miR-103a-3p serves a protective role in myocardial $I / R$ injury. Liu et al (28) demonstrated that miR-199a-5p expression affects hypoxia/reoxygenation-induced cytotoxicity in cardiomyocytes. Additionally, Peng et al (20) demonstrated that miR-133, miR-1291 and miR-663b expression was significantly increased in AMI compared with controls. However, the role and function of miR-663b in MI is yet to be fully elucidated. A previous study indicated that miR-663b is a tumor-associated miRNA (29). Cai et al (30) also demonstrated that miR-663b exerts a tumour suppressive effect by targeting insulin-like growth factor in pancreatic cancer. It has been reported that miR-663b expression was upregulated in osteosarcoma (31). In the present study, it was demonstrated that the expression of miR-663b was upregulated in hypoxia-induced H9c2 cells.

BCL2L1 was determined to be a direct target gene of miR-663b. Bcl2 genes are a mammalian family of genes that encode several proteins that directly regulate the activation of caspase-mediated apoptosis (32). As a member of this family, BCL2L1 acts as an antiapoptotic protein, with decreased expression activating a caspase cascade that ultimately promotes apoptosis. However, increased expression of BCL2L1 inhibits cell apoptosis (33). Sun and Pei (34) revealed that BCL2L1 is a target of miR-66 and increases vulnerability to propofol treatment in developing astrocytes. Lin et al (35) indicated that BCL2L1 was a target gene of miR-184 and that the miR-184 antagomir promoted apoptosis of osteosarcoma cells.

In the present study, BCL2L1 expression was downregulated at the mRNA and protein level in hypoxia-induced $\mathrm{H} 9 \mathrm{c} 2$ cells. The effects of miR-663b on cell injury, viability, apoptosis and the release of inflammatory factors in $\mathrm{H} 9 \mathrm{c} 2$ cells were also determined. Under hypoxic conditions, H9c2 cells were transfected with miR-663b inhibitor, inhibitor control, miR-663b inhibitor + control-siRNA or miR-663b inhibitor + BCL2L1-siRNA for $48 \mathrm{~h}$. The miR-663b inhibitor decreased the release of cardiomyocyte injury biomarkers CK-MB and cTnI and increased mitochondrial viability and cell viability while decreasing cell apoptosis and the secretion of the inflammatory factors IL-1 $\beta, \mathrm{TNF}-\alpha$ and IL-6. These effects were reversed by BCL2L1 knockdown.

In conclusion, the miR-663b inhibitor protected cardiomyocytes against hypoxia-induced damage by targeting BCL2L1. These data suggested that miR-663b may be a novel target for the treatment of MI, exerting its effects by directly targeting BCL2L1.

\section{Acknowledgements}

Not applicable.

\section{Funding}

No funding was received.

\section{Availability of data and materials}

The datasets used and/or analyzed during the present study are available from the corresponding author on reasonable request.

\section{Authors' contributions}

FY and XZ designed the study, collected the data, performed statistical analysis and data interpretation, and wrote the manuscript. CS (qRT-PCR, MTT data collection), WX (flow cytometry analysis and ELISA data collection) and JX (ELISA and MTT data collection) collected the data and prepared the manuscript. All authors read and approved the final version of this manuscript.

\section{Ethics approval and consent to participate}

Not applicable.

\section{Patient consent for publication}

Not applicable.

\section{Competing interests}

The authors declare that they have no competing interests.

\section{References}

1. Henriksson R, Björklund F and Mooe T: The introduction of ticagrelor is associated with lower rates of recurrent ischemic stroke after myocardial infarction. PLoS One 14: e0216404, 2019.

2. Zhang C, Zhang C, Wang H, Qi Y, Kan Y and Ge Z: Effects of miR-103a-3p on the autophagy and apoptosis of cardiomyocytes by regulating Atg5. Int J Mol Med 43: 1951-1960, 2019.

3. Zeymer U: Diagnosis and initial management of acute myocardial infarction. MMW Fortschr Med 161: 34-36, 2019.

4. Michiels C: Physiological and pathological responses to hypoxia. Am J Pathol 164: 1875-1882, 2004 (In German).

5. Ambros V: The functions of animal microRNAs. Nature 431: 350-355, 2004.

6. Bartel DP: MicroRNAs: Target recognition and regulatory functions. Cell 136: 215-233, 2009.

7. Poy MN, Eliasson L, Krutzfeldt J, Kuwajima S, Ma X, Macdonald PE, Pfeffer S, Tuschl T, Rajewsky N, Rorsman P and Stoffel M: A pancreatic islet-specifc microRNA regulates insulin secretion. Nature 432: 226-30, 2004.

8. Wang Q, Liu N, Yang X, Tu L and Zhang X: Small RNA-mediated responses to low- and high-temperature stresses in cotton. Sci Rep 6: 35558, 2016.

9. Lim LP, Lau NC, Garrett-Engele P, Grimson A, Schelter JM, Castle J, Bartel DP, Linsley PS and Johnson JM: Microarray analysis shows that some microRNAs downregulate large numbers of target mRNAs. Nature 433: 769-773, 2005.

10. Bartel DP: MicroRNAs: Genomics, biogenesis, mechanism, and function. Cell 116: 281-297, 2004.

11. Wang Y, Chen F, Zhao M, Yang Z, Zhang S, Ye L, Gao H and Zhang X: MiR-107 suppresses proliferation of hepatoma cells through targeting HMGA2 mRNA 3'UTR. Biochem Biophys Res Commun 480: 455-460, 2016.

12. Zhu Q, Gong L, Wang J, Tu Q, Yao L, Zhang JR, Han XJ, Zhu SJ, Wang SM, Li YH and Zhang W: miR-10b exerts oncogenic activity in human hepatocellular carcinoma cells by targeting expression of CUB and sushi multiple domains 1 (CSMD1). BMC Cancer 16: 806, 2016. 
13. Calin GA and Croce CM: MicroRNA signatures in human cancers. Nat Rev Cancer 6: 857-866, 2006.

14. Lu J, Getz G, Miska EA, Alvarez-Saavedra E, Lamb J, Peck D, Sweet-Cordero A, Ebert BL, Mak RH, Ferrando AA, et al: MicroRNA expression profiles classify human cancers. Nature 435: 834-838, 2005.

15. Liang S, Zhang N, Deng Y, Chen L, Zhang Y, Zheng Z, Luo W, Lv Z, Li S and Xun T: Increased serum level of MicroRNA-663 is correlated with poor prognosis of patients with nasopharyngeal carcinoma. Dis Markers 2016: 7648215, 2016.

16. Pan J, Hu H, Zhou Z, Sun L, Peng L, Yu L, Sun L, Liu J, Yang Z and Ran Y: Tumor-suppressive mir-663 gene induces mitotic catastrophe growth arrest in human gastric cancer cells. Oncol Rep 24: 105-112, 2010.

17. Jiao L, Deng Z, Xu C, Yu Y, Li Y, Yang C, Chen J, Liu Z, Huang G, Li LC and Sun Y: miR-663 induces castration-resistant prostate cancer transformation and predicts clinical recurrence. J Cell Physiol 229: 834-844, 2014.

18. Yi C, Wang Q, Wang L, Huang Y, Li L, Liu L, Zhou X, Xie G, Kang T, Wang H, et al: MiR-663, a microRNA targeting p21 (WAF1/CIP1), promotes the proliferation and tumorigenesis of nasopharyngeal carcinoma. Oncogene 31: 4421-4433, 2012.

19. Liang S, Zhang N, Deng Y, Chen L, Zhang Y, Zheng Z, Luo W, Lv Z, Li S and Xu T: miR-663b promotes tumor cell proliferation, migration and invasion in nasopharyngeal carcinoma through targeting TUSC2. Exp Ther Med 14: 1095-1103, 2017.

20. Peng L, Chun-guang Q, Bei-fang L, Xue-zhi D, Zi-hao W, Yun-fu L, Yan-ping D, Yang-gui L, Wei-guo L, Tian-yong $\mathrm{H}$ and Zhen-wen H: Clinical impact of circulating miR-133, miR-1291 and miR-663b in plasma of patients with acute myocardial infarction. Diagn Pathol 9: 89, 2014.

21. Gong L, Chang H, Zhang J, Guo G, Shi J and Xu H: Astragaloside IV protects rat cardiomyocytes from hypoxia-Induced injury by down-regulation of miR-23a and miR-92a. Cell Physiol Biochem 49: 2240-2253, 2018.

22. Livak KJ and Schmittgen TD: Analysis of relative gene expression data using real-time quantitative PCR and the 2(-Delta Delta c(T)) method. Methods 25: 402-408, 2001.

23. Thygesen K, Alpert JS, Jaffe AS, Simoons ML, Chaitman BR, White HD; Writing Group on the Joint ESC/ACCF/AHA/WHF Task Force for the Universal Definition of Myocardial Infarction; Thygesen K, Alpert JS, White HD, et al: Third universal definition of myocardial infarction. Eur Heart J 33: 2551-2567, 2012.

24. Chen Y, Zhao Y, Chen W, Xie L, Zhao ZA, Yang J, Chen Y, Lei W and Shen Z: MicroRNA-133 overexpression promotes the therapeutic efficacy of mesenchymalstem cells on acute myocardial infarction. Stem Cell Res Ther 8: 268, 2017.

25. Hu G, Ma L, Dong F, Hu X, Liu S and Sun H: Inhibition of microRNA-124-3p protects against acute myocardial infarction by suppressing the apoptosis of cardiomyocytes. Mol Med Rep 20: 3379-3387, 2019.
26. Luo Q, Guo D, Liu G, Chen G, Hang M and Jin M: Exosomes from MiR-126-overexpressing adscs are therapeutic in relieving acute myocardial ischaemic injury. Cell Physiol Biochem 44: 2105-2116, 2017.

27. Xiao X, Lu Z, Lin V, May A, Shaw DH, Wang Z, Che B, Tran K, Du $\mathrm{H}$ and Shaw PX: MicroRNA miR-24-3p reduces apoptosis and regulates Keap1-Nrf2 pathway in mouse cardiomyocytes responding to ischemia/reperfusion injury. Oxid Med Cell Longev 2018: 7042105, 2018.

28. Liu DW, Zhang YN, Hu HJ, Zhang PQ, and Cui W: Downregulation of microRNA-199a-5p attenuates hypoxia/reoxygenation-induced cytotoxicity in cardiomyocytes by targeting the HIF-1 $\alpha$-GSK3 $\beta$-mPTP axis. Mol Med Rep 19: 5335-5344, 2019.

29. Wang M, Jia M and Yuan K: MicroRNA-663b promotes cell proliferation and epithelial mesenchymal transition by directly targeting SMAD7 in nasopharyngeal carcinoma. Exp Ther Med 16: 3129-3134, 2018.

30. Cai H, An Y, Chen X, Sun D, Chen T, Peng Y, Zhu F, Jiang Y and He X: Epigenetic inhibition of miR-663b by long non-coding RNA HOTAIR promotes pancreatic cancer cell proliferation via up-regulation of insulin-like growth factor 2. Oncotarget 7: 86857-86870, 2016.

31. Zhao H, Li M, Li L, Yang X, Lan G and Zhang Y: MiR-133b is down-regulated inhuman osteosarcomaand inhibits osteosarcoma cells proliferation, migrationand invasion, and promotes apoptosis. PLoS One 8: e83571, 2013.

32. Fagundes DJ, Carrara FL, Teixeira WA, Simões RS and Taha MO: The role of the exogenous supply of adenosine triphosphate in the expression of Bax and Bcl2L1 genes in intestinal ischemia and reperfusion in rats1. Acta Cir Bras 33: 889-895, 2018.

33. Ureshino RP, Bertoncini CR, Fernandes MJ, Abdalla FM, Porto CS, Hsu YT, Lopes GS and Smaili SS: Alteratons in calcium signaling and a decrease in Bcl-2 expression: Possible correlaton with apoptosis in aged striatum. J Neurosci Res 88: 438-447, 2010.

34. Sun WC and Pei L: rno-miR-665 targets BCL2L1 (Bcl-xl) and increases vulnerability to propofol in developing astrocytes. J Neurochem 138: 233-242, 2016.

35. Lin BC, Huang D, Yu CQ, Mou Y, Liu YH, Zhang DW and Shi FJ: MicroRNA-184 modulates doxorubicin resistance in osteosarcoma cells by targeting BCL2L1. Med Sci Monit 22: 1761-1765, 2016.

This work is licensed under a Creative Commons Attribution-NonCommercial-NoDerivatives 4.0 International (CC BY-NC-ND 4.0) License. 